\title{
Socio-anthropological approach to the study of legal cultures: evolutionism and functionalism
}

\author{
Sergey Borisovich Zinkovsky ${ }^{1}$ \\ RUDN University, Law Institute, Department of Theory of Law and State, Moscow, Russia
}

\begin{abstract}
The purpose of the study is to substantiate the productivity of the socio-anthropological approach to the study of legal culture. In the study of legal cultures, the methodology of legal science involves going beyond both the special legal sciences and, in general, the social sciences. This actualizes the assessment of the productivity of the socio-anthropological approach to law and the justification of its evolutionist and functionalist directions for the conceptualization of legal phenomena. Their methodology in identifying the characteristics of legal culture is based on a) the recognition of its integral organism, whose elements are functionally connected and based on common principles; b) the principle of organicism, which involves the spread of methods, tools, and patterns of scientific knowledge, characteristic of the biological sciences, to social phenomena. This approach identifies the relationships between human thoughts and behavioral acts, biological and social processes, and various stages of the historical development of legal cultures. The result of the research is a structural scheme developed by the author, which demonstrates the productivity of the socio-anthropological approach to the study of legal culture, reflecting the main forms of manifestation of the reductionism of legal research from narrow methodological positions and ways to overcome it with the help of the socio-anthropological approach of evolutionist and functionalist orientation. The novelty of the work is due to the evolutionist and functionalist study of legal cultures applied by the author, which contributes to overcoming the limitations of criteria for the critical assessment of the laws of their development, contexts that allow characterizing legal phenomena from an interdisciplinary perspective, offer substantive and methodological alternatives to explain them and assess the importance of social communication processes in their dynamics.
\end{abstract}

Keywords: law and socio-anthropology, cross-cultural studies, primitive societies, cultural evolution, legal culture

\section{Introduction}

The study's background is based on the fact that the methods of scientific knowledge in general and legal phenomena, in particular, are based on the theory of knowledge, previous achievements, including their critical reflection. The process of development of the system

${ }^{1}$ Corresponding author: Zinkovskiy-sb@,rudn.ru 
of methods in legal science is subordinated to regularities of development of philosophy as an ideological basis of this branch of knowledge and includes the following stages: 1) cognition of being of law; 2) formation of ideas about methods of cognition of legal phenomena as a result of the 17th century revolution in philosophy and development of teachings on method of knowledge by R. Descartes and F. Bacon; 3) enrichment of subject and method of legal sciences due to interdisciplinary links with natural-science research as a result of the second revolution in 17th-18th century philosophy and development of experimental natural-science by G. Galileo and I. Newton; 4) the design of the system of methods of legal science, integrating philosophical foundations of law knowledge, general scientific principles of cognition, private-scientific methods, taking into account the specificity of the subject of legal science, which by the 20-21st centuries leads the researcher to the consideration of law through the prism of culture.

Different levels of methodological reflection in the field of legal culture research understood in the broadest sense of the word imply an appeal to the methods of ethnography, anthropology, and psychology [1]. Ethnography, which in the early stages of its development was part of geography, gives the researcher the basis for a hypothesis about the methodological connections between social and natural science. Anthropology allows viewing legal phenomena through the prism of evolutionism and functionalism. Psychology provides the basis for applying psychoanalytic methods and methods of cross-cultural psychological research in legal science.

The study hypothesis is the statement that in the study of legal cultures, the methodology of legal science involves going beyond both special legal and social sciences in general. The research hypothesis is based on the problem of the interdisciplinarity of legal knowledge and its connection with social and legal anthropology, ethnography, sociology, political science, and primatology, which is actively studied in modern science [2-6].

The purpose of the study is to substantiate the productivity of the socio-anthropological approach to the study of legal culture. The study's objectives are to assess the significance of a) evolutionist, b) functionalist directions of social anthropology to conceptualize legal phenomena.

\section{Methods}

The study is subject to the main laws of developing the socio-anthropological approach in the social sciences in general and in the legal sciences in particular. The nature and essence of legal phenomena are explained by referring to archaic forms of social organization and culture and by extrapolating the revealed patterns to the present.

Social anthropological research absorbs elements of various social sciences and humanities (anthropology, history, linguistics, psychology, etc.), thereby, though not without difficulties [7], revealing its particular scientific identity in the research field. It, in turn, corresponds to such commonly used research techniques as abstraction, ideal models, analogy, and extrapolation.

The explanation of legal culture from socio-anthropological positions proceeds from a) the recognition of it as an integral organism, whose elements are functionally connected and based on common principles; culture is a way of survival, so it is based on the patterns of functioning of living organisms, their interaction with the environment; in the center of such patterns is human, which together gives us the construction of the organism; b) the principle of organicism, which involves the spread of methods, tools, and patterns of scientific knowledge, characterizing the biological sciences, to social phenomena. 


\section{$3 \quad$ Results}

The results that demonstrate the productivity of the socio-anthropological approach to the study of legal culture are presented in a scheme that reflects the main forms of manifestation of the reductionism of legal research from narrow methodological positions and ways to overcome it with the help of the socio-anthropological approach of evolutionist and functionalist orientation.

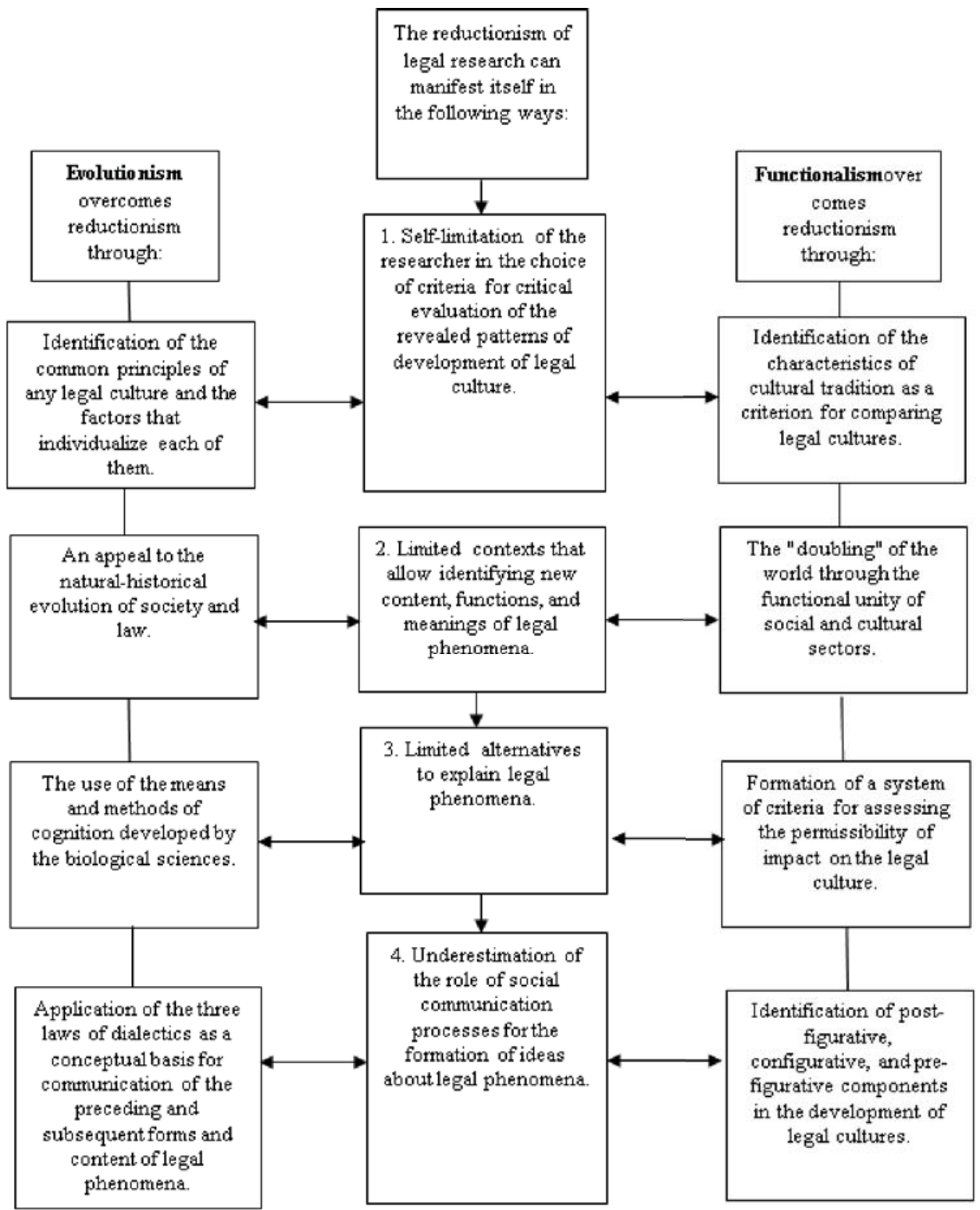

Fig. 1. The productivity of the socio-anthropological approach to the study of legal culture.

\section{Discussion}


The American comparativist Jeffrey Samuel formulated a controversial and noteworthy hypothesis that develops the importance of interdisciplinary studies of law. He analyzes the position of the French scientist Jean-Michel Berthelot, who believes that legal studies in the narrow sense of the word are dominated by judgments about the normative component of the law and not about the specifics of interpersonal interaction and human behavior as such [8]. P. Legrand, similarly, highlights the specifics of interdisciplinary legal research, which is expressed in the fact that they are aimed at establishing links between the norms of law and the cognitive structures that characterize society and are typical for it - the legal mentality [9]. According to D. Samuel, the goal of establishing such connections is not peculiar to legal studies in the narrow sense of the word, subject to the official, generally recognized paradigms that prevail in society, which "limit their ability to make an epistemological contribution to the ways of thinking inherent in the social sciences" [10]. Such studies aim only to identify, based on normative material, the principles of law and form a legal doctrine that plays a central role in the development of society's legal system.

The reductionism of legal research in the narrow sense of the word, in turn, limits the nature and significance of their results. The emphasis on the internal structure of the law, its normative component means the isolation of such studies in epistemological terms from other sciences; it entails 1) insufficiency of the "reference points" developed in other sciences for the criticism of the results of knowledge of legal phenomena; 2) avoiding the use of legal research in different contexts, which allows identifying new meanings of legal phenomena; 3) the fundamentalism in legal research, narrowing the search capabilities of research-based alternatives to explain legal phenomena; 4) inattention to the processes of intersubjective interaction (communication), which predetermine, along with individual consciousness, the specificity of understanding the essence of legal phenomena.

The socio-anthropological approach allows while preserving the continuity of the positivist methods that characterize legal research in the narrow sense of the word, to supplement them with organicism, evolutionism, and functionalism and overcome reductionism.

Socio-anthropological studies of law are based on empirical material and positivist methodology, which, in combination with the principle of organicism, allow identifying the phases of the development of legal culture, the patterns of transition from one phase to another, determining the interdependence of the elements of legal culture statically and dynamically.

Thus, positivist evolutionism (E. B. Taylor, J. Fraser, L. G. Morgan) helps to explain the diversity of legal cultures based on the laws of natural-historical evolution, identifying the common principles of any legal culture and the prerequisites for individualization of each of them - that is, based on a broad view of the context in which legal phenomena exist [11, 12]. Taylor E. B. believed that culture consists of knowledge, beliefs, morals, laws, customs, and habits through which a person is socialized [13]. Their specific combination individualizes the culture as a whole and the legal culture as its component. The phase structure of the development of legal cultures confirms a) the importance of the dialectical laws of unity and the struggle of opposites, the transition of quantity into quality and the negation of negation to explain the evolution of legal phenomena; b) the presence of common patterns in the development of various legal cultures.

The functionalism borrowed from biology in socio-anthropological research is objectively in demand since only in combination with it the evolutionist approach allows explaining the limits of influence on the elements of culture without compromising its integrity. Culture and its legal component are studied here in dynamics [14-16]. The definition of the components of culture that ensure its stability and reproduction comes to 
the fore. It is primarily a question of cultural tradition. Functionalism in the study of legal culture allows substantiating the functional unity of social and cultural institutions and proving that social needs condition the directions of their functioning. At the same time, any social phenomenon is part of the culture. However, if the social is limited to real facts, processes, and events occurring in society, then the cultural is much broader - it reflects how people imagine social life, reality. The functional unity of the social and cultural "doubles" the world - real legal phenomena and processes coexist with their ideal images, constructed through a conceptual and categorical series, ideas, theories, representations, assumptions. This "doubling" of the world has double refraction.

On the one hand, in developing legal phenomena, images can be created that do not reflect the surrounding reality and, in the process of their comparison with reality, lose their social significance. So, for example, it is possible to explain the loss of state power and the law of the sacred legitimacy in the early stages of the development of statehood and the Middle Ages. On the other hand, such images, without being rejected, can ensure the realization of the critical function of cognition of legal phenomena - when the surrounding reality is compared with them for certain purposes and through the conscious, purposeful actions of the subjects of public power is constructed in accordance with them. An example is the institutionalization of ideas about natural law in the state mechanism and the legal content of European states.

Functionalism in the study of legal phenomena explains that the prospects for intervention in the development of legal culture are not unlimited. Attempts to change the structure or content of the legal culture can lead to serious dysfunctions. The criterion determining the permissible degree of intervention is the functional necessity of the proposed changes. Only in this case, the culture does not reject them but adapts them. There are direct parallels with interference in the functioning of biological organisms. Adaptation of change culminates in its acquiring the status of an institution in response to a societal need.

These conclusions are confirmed in the theory of B. Malinowski, who argued that: a) in the study of the cultural aspects of social phenomena, the dynamics of culture and its relationship to the individual are important; b) the development of culture has in its basis a functional unity of the social and cultural, which determines the integrity of culture; c) not every phenomenon becomes an institution - it acquires this functional characteristic when it begins to fulfill the task of meeting social needs, the institution is always a set of roles and statuses; d) social needs are of both biological and social nature - cultural institutions are aimed at transforming the biological into the social, at narrowing the scope of biological instincts, at securing social ties and relationships; e) "the tasks of the specialist on prehistoric human, as well as the archaeologist, are to restore in integrity the vital realities of a bygone culture, based on fragmentary information derived from the examination of material remains... The share of scientificity in any anthropological work is the creation of a theory of culture, interrelated with the method of field observation and with the meaning of culture as a process and as a result" [17].

The regularities of the development of legal cultures can be identified based on the approach of the American researcher M. Mead. Analyzing the phenomenon of childhood, she proposed to consider three types of cultures - post-figurative (a less developed organism acquires experience from a more developed one), configurative (organisms of the same level of development exchange experience), and pre-figurative (more developed organisms perceive the experience of less developed ones) [18]. This typology is in harmony with the classification of areas of development of legal cultures. Here it is appropriate to speak not about the type of culture as a whole but about the post-figurative, configurative, and 
pre-figurative components in its development process. For example, the post-figurative model took place when the colonies perceived the system of sources of law in their mother countries. The configurative model manifests itself in the convergence of legal cultures, for example, within the European Union. The post-figurative model reveals itself in the restoration of traditional values as a factor in the development of statehood and law, for example, in the modern Russian legal culture.

\section{Conclusion}

The ideas of sociocultural evolution and the functional characteristics of its concurrent processes were established in Western European and North American science in the middle of the twentieth century. Socio-anthropological studies of legal phenomena have isolated a special subject space to explain the law as a cultural phenomenon. This approach has significant advantages in identifying the relationships between human thoughts and behavioral acts, biological and social processes, and various stages of the historical development of legal cultures. The concept of culture is a kind of "matrix" explaining the causes and mechanisms of the development of law.

Evolutionist and functionalist socio-anthropological studies of legal cultures allow for a comprehensive characterization of legal phenomena from an interdisciplinary perspective, offer substantive and methodological alternatives for explaining them, and assess the significance of social communication processes for understanding legal phenomena.

\section{References}

1. I. B. Przhilenskaya, Methodology and methods of culture research (Prospect, Moscow, 2021)

2. J. Bens, L. Vetters, Journal of Legal Pluralism and Unofficial Law, 50(3), 239-254 (2018). https://doi: 10.1080/07329113.2018.1559487

3. J. J. M. Lopez, Revista Espanola de Ciencia Politica-RECP, 39, 115-135 (2015)

4. G. Anders, Journal of Legal Pluralism and Unofficial Law, 47(3), 411-422 (2015). https://doi: 10.1080/07329113.2015.1110909

5. P. Riley, American Anthropologist, 115(3), 411-422 (2013). https://doi: 10.1111/aman.12025

6. B. Rivaya, Quaestio Iuris, 12(4), 217-246 (2019). https://doi: 10.12957/rqi.2020.43119

7. C. Brkovic, Anthropological Journal of European Cultures, 29(2), 31-48 (2020). https://doi: 10.3167/ajec.2020.290203

8. J.M. Berthelot (ed.), Épistémologie des Sciences Sociales, 12 (Presses Universitaires de France, Paris, 2001)

9. P. Legrand, Le Droit Comparé (Presses Universitaires de France, Paris, 1999)

10. G. Samuel, Cambridge Law Journal, 67(2), 288 (2008)

11. L. Holden, Law and History Review, 38(1), 29-46 (2020). https://doi: 10.1017/S073824801900049X

12. A. Reed, J. Bialecki, Social Anthropology, 26(2), 159-167 (2018). https://doi: 10.1111/1469-8676.12479

13. E.B. Taylor, Primitive culture (Politizdat, Moscow, 1989) 
14. F. Carler, J.F. Ferreira, Onati Socio-Legal Series, 8(5), 647-676 (2018). https://doi: 10.35295/osls.iisl/0000-0000-0000-0965

15. V.Gutorov, A. Koryushkin, K. Zavershinskiy, Politologicky Casopis-Czech Journal of Political Science, 26(2), 83-101 (2019). https://doi: 10.5817/PC2019-2-83

16. C. Simon, B. Truffin, A. Wyvekens, Between Norms, Facts, and Stereotypes: The Place of Culture and Ethnicity in Belgian and French Family Justice, in Cultural Expertise and Socio-Legal Studies, 113-129 (Emerald Publishing Limited, Bredford, 2019)

17. B. Malinovsky, Scientific theory of culture (OGI, Moscow, 2005)

18. M. Mead, Culture and the world of childhood (Science, Moscow, 1988) 